\title{
A prática arquivística: os métodos da disciplina e os documentos tradicionais e contemporâneos
}

\section{Leandro Ribeiro Negreiros}

\author{
Mestre em Ciência da Informação pela \\ Escola de Ciência da Informação da \\ Universidade Federal de Minas Gerais - \\ Brasil.
}

Eduardo José Wense Dias

Doutor. Professor titular da Escola de Ciência da Informação da Universidade Federal de Minas Gerais - Brasil.

Apresentam-se os métodos e procedimentos realizados em arquivos, relacionando as diferenças do tratamento de documentos arquivísticos tradicionais e eletrônicos. $O$ caráter de evidência, o público alvo a que se destinam os documentos arquivísticos, a preservação, o sigilo e a segurança são apontados como premissas que embasam o trabalho de arquivistas. Conclui-se que, com a introdução das novas tecnologias e dos documentos produzidos em meio eletrônico, os processos arquivísticos não sofreram grandes modificações; ao contrário, abriram-se para uma nova realidade em que o acesso é privilegiado.

Palavras-chave: Documento arquivístico; Documento arquivístico eletrônico; Prática arquivística.

\section{Archival practice: methods of the discipline and traditional and contemporary documents}

The methods and procedures carried through in archives are presented, showing the differences in the treatment of traditional and electronic archival documents. The evidence trait, the audience to which archive documents are targeted, preservation and secrecy, and security are pointed as basic premises for the work of archivists. It is 
concluded that archival processes had not suffered great modifications with the introduction of new technologies and document production in electronic media, but rather, a new reality was opened where the access is privileged.

\section{Keywords: Archival document; Electronic archival document; Archival practice.}

Recebido em 30.05.2008 Aceito em 13.10.2008

\section{Introdução}

A transformação histórica da arquivologia é, evidentemente, marcada pelo pragmatismo. A disciplina formou-se a partir de soluções de problemas práticos que a teoria se encarregou, mais tarde, de explicar, analisar e compreender. Primeiro, porque documentos de arquivo são fruto das atividades humanas e, inevitavelmente, produzidos; depois, porque a arquivologia esteve sempre a reboque de outras disciplinas como a diplomática, o direito, a administração e a história.

O arquivo foi visto, primeiramente, como um local onde se armazenavam os documentos produzidos pela administração e que possuíam valor jurídico. Mais tarde, os documentos arquivísticos foram reconhecidos como instrumentos de poder, e seu significado histórico também percebido, voltando-se olhares mais atentos para a massa documental acumulada (MORENO, 2004). Esta, por sua vez, crescia juntamente com os avanços tecnológicos e com a necessidade informacional, ocasionando um avanço na teoria arquivística - o nascimento da gestão de documentos arquivísticos - e um desafio: a organização dos documentos arquivísticos. Os arquivos passaram a ser vistos, então, como sistemas e as tecnologias da informação tornaram-se ferramentas essenciais para a sua gestão. O surgimento de documentos produzidos em meio eletrônico veio tornar ainda mais complexo esse cenário de produção, utilização e armazenamento de documentos arquivísticos.

A concepção de "documento de arquivo", até então proposta, adequou-se bem a uma cultura que aceitava o papel como suporte primordial e capaz de, com auxílio de outros instrumentos legais, conferir autenticidade e fidedignidade aos documentos. Mas o aparecimento de documentos produzidos em meio eletrônico apresentou novos desafios, principalmente na tarefa de se conferir valores probatórios e jurídicos aos mesmos.

O National Archives and Records Administration (NARA) define o documento arquivístico eletrônico como "any information that is recorded in a form that only a computer can process and that satisfies the definition of a record"1 ${ }^{1}$ (NARA, 2005). O Conselho Nacional de Arquivos (CONARQ,

\footnotetext{
1 "Qualquer informação registrada de forma tal que somente um computador possa processar e que satisfaça à definição do que é um documento" (tradução nossa).
} 
2004), através de seu "Glossário de documentos digitais", desenvolvido pela Câmara Técnica de Documentos Eletrônicos, define documento arquivístico digital como um "documento arquivístico codificado em dígitos binários, produzido, tramitado e armazenado por sistema computacional".

Dessas definições, é possível depreender que o suporte é eletrônico e a informação, ou seja, o conteúdo do documento, somente é acessível através do auxílio de um computador. Por isso, pode-se entendê-la também como uma informação que só existe em meio eletrônico e, mesmo assim, deve ainda conter as características dos documentos arquivísticos tradicionais. Sendo assim, independente de ser ou não um documento eletrônico, para ser um documento arquivístico o mesmo precisa respeitar os princípios e as características dos documentos arquivísticos ditos convencionais. Dollar (1994, p.20) afirma que a "preservação de documentos eletrônicos exige que se mude a ênfase da preservação dos registros ou dos meios de armazenagem física para o acesso à informação eletronicamente apreendida, armazenada e recuperada".

A prática em arquivos - evidenciada pelas atividades de identificação, classificação, avaliação, arranjo, descrição, preservação, transferência e recolhimento, arquivamento e disseminação da informação - tem seus questionamentos diante da sobreposição de uma realidade consolidada (com os documentos tradicionais) e de um novo cenário apresentado: o dos documentos arquivísticos produzidos, utilizados e armazenados em ambiente eletrônico.

O objetivo do presente artigo é o de apresentar os métodos e procedimentos realizados em arquivos, procurando mostrar as diferenças entre o trabalho de organização realizado com documentos arquivísticos tradicionais e com documentos eletrônicos.

Tal empenho justifica-se, primeiramente, para que a prática seja um reflexo de uma teoria consolidada que se preocupa em analisar os impactos causados pelas tecnologias da informação e o aparecimento e proliferação de documentos produzidos em meio eletrônico nos princípios e técnicas arquivísticas. Depois, para "desmistificar" o documento eletrônico como um documento incapaz de manter as características que fariam dele um documento arquivístico, quais sejam: autenticidade, fidedignidade, naturalidade, inter-relacionamento e unicidade (RONDINELLI, 2005) ${ }^{2}$. 


\section{As prioridades da arquivologia: o quadrilátero em que se assenta a prática da disciplina}

Todo e qualquer método arquivístico é realizado tendo como base algumas premissas. Estas premissas diferenciam, por exemplo, um documento de biblioteca, museu ou centro de documentação, de um documento de arquivo, e refletem as preocupações evidentes da disciplina com relação à produção, ao uso e ao armazenamento de documentos. São quatro as prioridades da arquivologia, a saber:

10 documento como prova de um ato ou fato:

Para a arquivologia, é fundamental compreender um documento arquivístico pela evidência que este comprova. Diferente da biblioteconomia, o foco não está na informação, mas no documento como figurante da existência de um ato e de suas repercussões administrativas, fiscais e legais. A questão informacional é uma conseqüência, mas não uma prioridade. O Arquivo Nacional (2005) atribui diversos valores aos documentos arquivísticos que estão conectados ou que conferem aos mesmos sua especificação como prova documental:

Valor administrativo: valor que um documento possui para a atividade administrativa de uma entidade produtora, na medida em que informa, fundamenta ou prova seus atos.

Valor fiscal: valor atribuído a documentos ou arquivos para comprovação de operações financeiras ou fiscais.

Valor legal: valor que um documento possui perante a lei para comprovar um fato ou constituir um direito.

Valor probatório: valor intrínseco que permite a um documento de arquivo servir de prova legal.

Duranti (1994, p. 50) afirma:

Essa capacidade dos registros documentais de capturar os fatos, suas causas e conseqüências, e de preservar e estender no tempo a memória e a evidência desses fatos, deriva da relação especial entre os documentos e a atividade da qual eles resultam, relação essa que é plenamente explorada no nível teórico pela diplomática e no nível prático por numerosas leis nacionais.

2 Comunidade ou público-alvo:

Se, em bibliotecas e museus, a gama de usuários é extremamente variada e de difícil determinação (usuários de uma biblioteca pública estadual podem ser tanto aqueles residentes na cidade onde está localizada, quanto os que habitam o estado que a abrange, ou até mesmo 
toda a população do país, por exemplo), em arquivos, fala-se mais de comunidade ou público-alvo. Isto se deve ao fato de que a organização que produz, recebe, utiliza e preserva documentos arquivísticos tem um número reduzido ou limitado de pessoas que poderão fazer uso desses documentos. Aqueles produzidos ou recebidos por essa organização estarão intimamente ligados às atividades e funções desenvolvidas por seus utilizadores. O conjunto desses usuários pode-se chamar de comunidade, que poderá ser formada por membros de uma família, quando se tratar de um arquivo pessoal; membros de uma organização, quando se tratar de um arquivo particular ou de uma empresa ou, ainda, membros da sociedade, quando se tratar de um arquivo público. Mesmo nesse último caso, apesar de pouco específica, esta comunidade terá que manter relações com a produção ou a utilização dos documentos custodiados por esse arquivo público, ou seja, os cidadãos terão acesso aos documentos em que são uma das partes relacionadas e envolvidas nos fatos que esses itens atestam.

\section{Preservação:}

A prioridade para a arquivologia é a preservação dos documentos. Isto compreende, em um primeiro momento, que haja precaução contra a deterioração e danos aos documentos e, em um segundo momento - e talvez seja esse o maior desafio nesse contexto eletrônico de produção de documentos - que haja preservação das características dos documentos arquivísticos. O acesso aos documentos, sua identificação e sua localização, ou seja, a recuperação da informação, é importante, mas a partir do momento em que a preservação - física e intelectual - foi assegurada.

\section{Sigilo e segurança:}

Se, em bibliotecas, prima-se pela manutenção, preservação e validação do direito autoral, em arquivos as prioridades estão lançadas em favor do sigilo da informação contida no documento e na segurança, ou seja, na proteção para a não violação desses documentos considerados, de acordo com a função ou a atividade que os geraram, sigilosos. Documentos sigilosos são aqueles a que, pela natureza de seus conteúdos, são atribuídos graus de sigilo, com o objetivo de limitar ou restringir 0 acesso a eles. $O$ ato de atribuir a documentos, ou às informações neles contidas, graus de sigilo, é também chamado de classificação de segurança (ARQUIVO NACIONAL, 2005). Em cada uma das fases do ciclo vital, os documentos podem ter seus graus de sigilo modificados, de acordo com os fatos e atos que atestam.

Essas premissas devem ser consideradas ao se pensar e realizar os métodos e procedimentos próprios da arquivologia. São essas prioridades que indicarão as diferenças substanciais entre um processo de descrição 
arquivístico e um processo de descrição bibliográfica, por exemplo. Nesse caso, a tarefa de se descrever um documento arquivístico se baseará: a) nas suas características de elemento de prova, que confere evidência a um ato ou a um fato; b) no público-alvo que fará uso desse documento e, conseqüentemente, nos graus de sigilo e nas medidas de segurança que deverão ser tomadas de acordo com seus usuários e suas necessidades/possibilidades de acesso; e c) na sua preservação, para que seja acessado futuramente, ou para que seja utilizado em decorrência de outras necessidades diferentes das que o geraram.

\section{A prática arquivística: o fazer arquivístico e as especificidades do documento tradicional e contemporâneo}

Os procedimentos arquivísticos aqui apresentados serão discutidos relacionando-se as definições das atividades e suas nuances no tratamento de documentos tradicionais e eletrônicos.

\subsection{Identificação}

Tal atividade ocorre na primeira fase da idade documentária, definida como corrente, e a ela cabe a identificação da tipologia e das funções a que se referem os documentos. Ou seja, nesta fase é preciso definir a que vieram os documentos, "a quem ou a que órgãos cabem o trâmite, que legislação regula sua vida ativa, que informação essencial contém e qual seu papel na teia orgânica da administração a qual o arquivo serve" (BELLOTO, 1991, p. 10).

Cabe à identificação conferir unicidade ao documento. Ou seja, mesmo que haja cópias, o documento é único no conjunto (fundo, série, dossiê) ao qual pertence. Os instrumentos utilizados nesse processo são: os organogramas, os quadros de fluxos de informação, as normas que estabeleçam as atividades de cada setor ou órgão (quando se tratar de organizações públicas), enfim, instrumentos que têm suas origens, assim como os documentos, dentro da própria organização.

Tanto para documentos produzidos em meio eletrônico quanto para os tradicionais, a identificação objetiva a determinação de quais atividades e funções originaram, de quem são seus autores e a que se destinam. Esse processo está intimamente ligado à classificação e independe do formato do documento, mas sim do contexto de sua produção e acumulação. Nos sistemas informatizados de gerenciamento de documentos (SIGAD) os documentos eletrônicos recebem identificadores únicos, que distinguem um documento eletrônico de outros e que se reportam a todo o sistema ou à hierarquia a qual pertencem (EUROPEAN COMMISSION, 2002). 


\subsection{Classificação}

No âmbito da arquivologia, a classificação pode atingir três níveis diferentes de significado:

organização dos documentos de um arquivo ou coleção, de acordo com um plano de classificação, código de classificação ou quadro de arranjo. 2- Ato ou efeito de analisar e identificar o conteúdo dos documentos, selecionar a categoria de assunto, sob a qual sejam recuperados, podendo-Ihes atribuir códigos. 3- Ato pelo qual se atribui a documentos, ou às informações neles contidas, graus de sigilo, conforme a legislação específica. Também chamado de classificação de segurança (ARQUIVO NACIONAL, 2005).

O primeiro e o segundo significados se aproximam da definição de classificação em bibliotecas, ou seja, correspondem à organização dos itens informacionais no que tange ao acondicionamento e à localização temática. Fique claro que a disposição dos documentos de arquivos numa estante, por exemplo, deve seguir as funções e as atividades que os geraram dentro da organização, naquilo que na definição do Arquivo Nacional (2005) ficou determinado por "plano de classificação", "código de classificação" e "quadro de arranjo". Na terceira acepção, classificação passa a se apresentar como fator relevante para a determinação do acesso aos itens informacionais; não relacionada apenas ao suporte físico, mas, principalmente, ao conteúdo. O segundo significado atribuído à classificação denota certa ambigüidade, podendo ser interpretado ou confundido com o processo de indexação realizado em bibliotecas. Para Bellotto (1991), "a fase que em bibliotecas e em arquivos correntes se denomina classificação corresponde, nos arquivos de segunda e terceira idades, ao que se chama arranjo ou ordenação" (p.17).

A classificação pode ocorrer tanto na fase corrente - como uma conseqüência da identificação -, quanto na fase permanente, com a constituição do fundo. O plano de classificação, mesmo que configurado para funcionar automaticamente dentro de um SIGAD, parte de uma concepção subjetiva, em que a presença do arquivista é indispensável. 0 plano de classificação define a organização do arquivo, tendo como base a estrutura, as funções, as atividades, as tipologias documentais e a complexidade da instituição que o configurou.

Em um SIGAD, o funcionamento do plano de classificação, o da tabela de temporalidade e a atribuição de categorias de segurança devem funcionar conjuntamente para que se cumpram as três funções da classificação em arquivos: determinar a posição do documento na estrutura organizacional $e$, conseqüentemente, sua localização física ou lógica; identificar o conteúdo do documento, de acordo com o assunto a que se refere (função e atividade); e atribuir graus de sigilo. São, na grande maioria dos sistemas existentes, os metadados (veja a definição 
adiante) os responsáveis pela gestão da estrutura, da organicidade dos documentos e dos prazos de guarda e destinação.

Percebe-se, portanto, que a classificação independe do formato do documento arquivístico. Está, pois, intimamente ligada ao contexto, à estrutura e ao conteúdo do documento.

\subsection{Avaliação}

O acúmulo de documentos levou ao desenvolvimento de técnicas e instrumentos que permitem a eliminação de documentos arquivísticos para que haja uma sistematização do arquivamento daqueles considerados de valor permanente, diminuindo custos com espaço, armazenamento e pessoal. Tais atividades, que ocorrem nas fases corrente e intermediária, estão relacionadas à subjetividade humana de análise e decisão:

De modo geral, a eficácia de um programa de redução de documentos pode ser avaliada de acordo com a correção de suas determinações. Num programa dessa natureza não há substituto para o cuidadoso trabalho de análise. Não há possibilidade de serem inventadas técnicas que reduzam o trabalho de decidir sobre os valores dos documentos a uma operação mecânica (SCHELLENBERG, 2002, p. 180).

Sendo assim, a avaliação compreende, segundo o Arquivo Nacional (2005), um "processo de análise de documentos de arquivo, que estabelece os prazos de guarda e a destinação, de acordo com os valores que Ihes são atribuídos". O Arquivo Nacional (1995) afirma que tal processo objetiva a redução da massa documental, o aumento do índice de recuperação da informação, a qualidade de conservação dos documentos permanentes, o controle do processo de produção documental, a melhor utilização do espaço físico de armazenamento, o aproveitamento de recursos humanos e materiais, e a garantia de constituição do patrimônio arquivístico da organização.

A seleção compreende a separação dos documentos de valor permanente daqueles passíveis de eliminação, respeitando critérios previamente estabelecidos (ARQUIVO NACIONAL, 2005). Esses critérios determinam os períodos que os documentos devem ser mantidos em cada uma de suas fases de seu ciclo vital e sua possível eliminação. A freqüência de uso das informações contidas nos documentos, a legislação que regula os prazos prescricionais, a existência de documentos recapitulativos e os prazos precaucionais serão fatores condicionantes da determinação dos prazos de guarda.

Com documentos eletrônicos, é comum que as atividades de avaliação e seleção se iniciem juntamente com o ciclo de vida desses documentos, ainda no estágio de produção. Isto porque os requisitos de retenção e destino devem ser configurados ainda na implementação do SIGAD. O potencial de se avaliar e selecionar os documentos arquivísticos 
depois de cessado o valor primário de utilização dos mesmos inexiste no ambiente eletrônico (INTERNATIONAL COUNCIL ON ARCHIVES ICA, 1997).

Peterson (1984) aponta que a avaliação e a seleção dos novos formatos de documentos têm dois aspectos, a saber: o intelectual e o prático. $O$ intelectual responsabiliza-se pelas questões relacionadas à informação: valores de prova e valores informacionais e é idêntico para qualquer documento e em qualquer formato. O lado prático da avaliação e da seleção cuida das preocupações oriundas de como armazenar os documentos arquivísticos, o quanto isto custará, com qual freqüência eles terão que ser transferidos, se a amostragem arquivada representa a verdade dos fatos que os originaram e se o pesquisador os utiliza sempre.

As determinações dos processos de avaliação e seleção são dispostas em instrumento apropriado para uso nessas atividades: a tabela de temporalidade.

\subsection{Tabela de Temporalidade}

A tabela de temporalidade é o instrumento que define o ciclo de vida do documento, visando reduzir ao máximo a interferência da subjetividade humana no processo de decisão de retenção ou eliminação. Tal instrumento define ainda os prazos e as condições de guarda, preocupando-se em determinar os períodos de transferência, recolhimento e eliminação.

Elaborada a partir da análise dos documentos existentes na instituição e de sua utilização, a tabela de temporalidade pretende a separação dos documentos de guarda temporária daqueles permanentes; a eliminação dos documentos cuja guarda não seja necessária; a racionalização das atividades de transferência e recolhimento e a implementação de uma política de destinação de documentos (ARQUIVO NACIONAL, 1995). É utilizada, portanto, nas fases corrente e intermediária.

Com o surgimento dos documentos arquivísticos produzidos em meio eletrônico, a tabela de temporalidade ganhou, além de seus dados básicos (órgão, setor, espécie e assunto do documento, prazos de guarda, destinação etc.), outros complementares, que dizem respeito à obsolescência tecnológica, ou seja, algumas observações a respeito da migração de suportes e transferência de mídias. A grande facilidade apresentada pelos sistemas informatizados é a possibilidade de se ter várias tabelas de temporalidade gerenciando os documentos contidos no sistema. Dessa maneira, é possível obter automaticamente relatórios de documentos tradicionais e eletrônicos a serem eliminados, transferidos ou recolhidos para a guarda permanente. Entretanto, cuidado deverá ser tomado com os documentos eletrônicos, cuja eliminação poderá ser fatal. Assim, a tabela de temporalidade "anunciará" os documentos com prazo de guarda vencido, e só com a aprovação do administrador do sistema se deverá proceder à eliminação. 


\subsection{Arranjo}

Entende-se por arranjo a "seqüência de operações intelectuais e físicas que visam à organização dos documentos de um arquivo ou coleção, utilizando-se diferentes métodos, de acordo com um plano ou quadro previamente estabelecido" (ARQUIVO NACIONAL, 2005). Paes (2005) afirma que as operações intelectuais compreendem a análise dos documentos quanto a sua origem funcional, forma e conteúdo; e as operações físicas referem-se ao acondicionamento dos suportes documentais em locais apropriados e à identificação dos mesmos para definir sua disposição. $O$ estudo das funções, das atividades e da estrutura da organização produzirá um esquema chamado quadro de arranjo que auxiliará nas atividades intelectuais e físicas de arranjo, realizadas na fase permanente.

O arranjo de documentos eletrônicos, assim como no contexto tradicional, estará intimamente ligado a manutenção da proveniência. Mesmo que o documento não esteja agora disposto em estantes ou gavetas, mas em inventários ou repositórios da memória de um computador, arranjá-lo significa ainda ordená-lo de acordo com as atividades e funções que o geraram. Bearman (1993) afirma que, no arranjo físico, remover um documento de seu local de acondicionamento representa sério risco para o bom cumprimento do princípio de proveniência. Com os documentos eletrônicos ocorre o mesmo. Peterson (1984) chega a afirmar que a disposição do documento eletrônico num repositório depende da conveniência administrativa e não do formato, garantindo-se assim que a estrutura e a informação do contexto que gerou a documentação possam ser preservadas.

\subsection{Descrição}

$\mathrm{Na}$ arquivologia, ocorre uma discussão que envolve dois termos diferentes para designar a mesma atividade: catalogação e descrição. "A catalogação, via pela qual o usuário chega a uma publicação [...] na biblioteca [...], tem seu similar, quando se trata de arquivos permanentes, na descrição" (BELLOTTO, 1991, p. 17). No Brasil, o Arquivo Nacional (2005) define descrição como sendo um...

"...conjunto de procedimentos que leva em conta os elementos formais e de conteúdo dos documentos para a elaboração de instrumentos de pesquisa", e, em sua definição de catálogo, define-o da seguinte maneira: "instrumento de pesquisa organizado segundo critérios temáticos, cronológicos, onomásticos ou toponímicos, reunindo a descrição individualizada de documentos pertencentes a um ou mais fundos, de forma sumária ou analítica". 
Sendo assim, pode-se concluir que, preferencialmente, utiliza-se o termo descrição para o processo de representação do documento em arquivos permanentes. É mais comum, no entanto, utilizar-se em arquivos o termo "catálogo", como sendo um instrumento de pesquisa mais elaborado do que um simples conjunto de representações dos documentos encontrados no fundo. $E$, por se tratar de documentos com valor histórico, o catálogo transforma-se em "vias de acesso do historiador ao documento, sendo a chave da utilização dos arquivos como fontes primárias da história" (BELLOTTO, 1991, p. 17).

Bearman (1993, p. 24) cita o SAA Ad Hoc Committee on Description Practices(1989)ㅡㅗ para definir a descrição arquivística como:

"the process of capturing, collating, analyzing, and organizing any information that serves to identify, manage, locate, and interpret the holdings of archival institutions and explain the contexts and record systems from which those holdings were selected $\underline{4}^{\prime \prime}$.

No ambiente eletrônico, a descrição ganha ainda maior destaque nas funções de preservação e acesso aos documentos. Como o acesso ao conteúdo dos documentos eletrônicos está condicionado à sua exibição através da ajuda de um aplicativo de software, faz-se uso da descrição do documento eletrônico para recuperá-lo previamente. A descrição se encarrega também de determinar como foram concebidos os documentos (aplicativo, fonte, tipo de documento etc.), através dos elementos de metadados; e é também através desses mesmos elementos que se reconstitui a proveniência do documento eletrônico. Observa-se que a descrição terá, portanto, três funções: representar o documento; caracterizá-lo (segundo o suporte e a tecnologia utilizada) para posterior conservação e preservação; e localizá-lo dentro da estrutura organizacional. Todo esse processo será possível por meio dos metadados.

Ikematu (2005, p. 1), discutindo sobre gestão de metadados, os define, entre outras acepções, das seguintes maneiras:

- Metadados são dados que descrevem atributos de um recurso. Eles suportam um número de funções: localização, descoberta, documentação, avaliação, seleção etc. ;

- Metadados fornecem o contexto para entender os dados através do tempo.

\footnotetext{
${ }^{3}$ Reports of the Ad Hoc Committee on Descriptive Standards, American Archivist, 52, n. 4, 1989 e American Archivist, 53, n. 1, 1990. O Comitê de Padrões de Descrição Arquivística é um dos comitês da Sociedade dos Arquivistas Americanos (The Society of American Archivists).

4 "O processo de coletar, reunir, analisar e organizar qualquer informação que sirva para identificar, gerenciar, localizar e interpretar as coleções das instituições arquivísticas, bem como para explicar os contextos e sistemas de registro a partir dos quais essas coleções foram selecionadas." (tradução nossa).
} 
Percebe-se que os metadados são elementos utilizados para a descrição, que servirão tanto ao suporte, ou seja, o meio pelo qual o documento é disposto, quanto ao conteúdo. MacNeil (2000) $\underline{5}$, citado por Rondinelli (2005, p. 61), distingue duas categorias de metadados:

A primeira categoria, metadados do sistema eletrônico, consiste em dados que descrevem o sistema operacional, o programa que gera os documentos, a localização física dos documentos no sistema eletrônico (...) A segunda categoria, metadados dos documentos, por outro lado, consiste em dados que colocam o documento dentro do seu contexto documentário e administrativo no momento da sua criação (...) Em alguns sistemas eletrônicos, tais dados são armazenados no dicionário de dados; em outros são reunidos num perfil do documento anexado ao documento arquivístico.

Bearman, em 1993, já se preocupava com a descrição de documentos eletrônicos e a manutenção do princípio de proveniência através dos metadados. Sendo assim, suas palavras preconizam aquilo que MacNeil destaca como a segunda categoria de metadados: "metadata documenting a record system needs to link organizational structure and function, business and archival processes, software procedures, and documentary forms $\underline{6}^{\S "}$.

Cabe aos metadados, portanto, preservar a proveniência do documento eletrônico; resguardar as características da forma e do suporte da tipologia dos documentos; recuperar a sua relação orgânica e seu contexto de produção; definir os responsáveis (pessoas físicas ou jurídicas) pela produção do item; e descrever sinteticamente o conteúdo.

Bearman (1996?), em trabalho realizado na University of Pittsburgh, denominado "Metadata requirements for evidence" $\underline{\underline{ }}$, afirma que algumas exigências funcionais ditam que os documentos sejam detalhados, identificados, completos (no que se refere à estrutura e ao contexto) e com autoridade de produção reconhecida. Essas exigências permitiriam especificar quais metadados seriam necessários para garantir que os documentos sejam preservados ao longo do tempo e que sua utilidade seja viável por meio de sucessivas gerações de software, enquanto mantidos em um SIGAD.

MACNEIL, H. Trusting records: legal, historical and diplomatic perspectives. Dordrecht: Kluwer Academic, 2000.

6 "É preciso que os metadados que documentam um sistema de registros conectem a estrutura e a função organizacionais, os processos empresariais e arquivísticos, os procedimentos de software e as formas documentais" (tradução nossa).

7 "Requisitos de metadados para evidência" (tradução nossa). 


\subsection{Preservação}

Quando se discute guarda permanente de documentos, não se espera que os documentos sejam mantidos intactos por toda a eternidade, mas que sejam guardados e protegidos de tal maneira que se estenderá seu uso e acesso ao máximo, até que seu valor primário seja superado e seu valor secundário seja utilizado em pesquisas ou em outras atividades de tomada de decisão.

Conway (2001, p. 14) afirma que preservação é "a aquisição, organização e distribuição de recursos a fim de que venham a impedir posterior deterioração ou renovar possibilidade de utilização de um seleto grupo de materiais". Para o autor, a preocupação está com o objeto propriamente e com a noção de evidência que este carrega, independente da fase do ciclo vital em que se encontra o documento arquivístico. Portanto, administrar a preservação "compreende todas as políticas, procedimentos e processos que evitam a deterioração ulterior do material de que são compostos os objetos, prorrogam a informação que contêm e intensificam sua importância funcional" (CONWAY, 2001p. 14).

A vida relativamente curta do hardware e do software tem implicações importantes para a preservação em longo prazo dos documentos eletrônicos. As organizações, por exemplo, substituem seus sistemas quando estes se tornam obsoletos ou quando novos produtos superam as vantagens do antigo software. Preservação, nesse sentido, assume uma nova conotação, ou seja, significa assegurar que os documentos criados e mantidos no antigo sistema de gerenciamento permaneçam compreensíveis e usáveis no novo sistema a partir da migração dos registros.

Essa migração implica incompatibilidade de configurações, mesmo que os sistemas possuam o chamado mecanismo de "compatibilidade inversa" ${ }^{8}$. Sistemas complexos, que foram desenvolvidos de acordo com requisitos não-funcionais ${ }^{9}$ específicos para uma organização, são mais difíceis de migrar e se compatibilizar com os novos sistemas. Além de dispendioso financeiramente, esse processo de migração requer mudanças substanciais para que a estrutura e o formato dos documentos não sejam prejudicados e não comprometam sua integridade como evidência. Considerar um documento eletrônico como preservado significa que este documento pode ser acessado e, quando feito, permita evidenciar a atividade que o produziu com confiabilidade e autenticidade (ICA, 1997). Como afirma Conway (2001, p. 15), "a preservação no universo digital descarta toda e qualquer noção dúbia que entenda preservação e acesso como sendo atividades distintas".

Função que promete realizar a migração sem perdas significativas para o SIGAD.

Requisitos não-funcionais são aqueles que deverão ser definidos de acordo com as exigências das organizações que implementarão um sistema informatizado de gerenciamento arquivístico de documentos, de acordo com a estrutura de cada uma, bem como de suas características físicas e o ambiente operacional técnico. Tais requisitos referem-se mais especificamente à usabilidade, desempenho do sistema, disponibilidade do sistema, normas técnicas e regulamentares, obsolescência tecnológica, etc. 
Por mais que estejam preservados os meios físicos (disquetes, discos ópticos, fitas magnéticas etc.), isso não significa que o documento eletrônico esteja preservado (ICA, 1997).

\subsection{Transferência e recolhimento}

Reconhece-se como transferência a passagem dos documentos do arquivo corrente para o arquivo intermediário, e, como recolhimento, 0 deslocamento dos documentos do arquivo intermediário para o arquivo permanente (ARQUIVO NACIONAL, 2005; CONARQ, 2004; PAES, 2005). Tais processos ocorrem de acordo com a freqüência de uso e o valor do documento, objetivando o aproveitamento dos espaços físicos, economizando recursos materiais e pessoais e facilitando o acesso e a preservação dos documentos (PAES, 2005).

Talvez numa concepção "jenkinsoniana" de arquivos - que expressa continuidade no ciclo dos documentos e não separa os produzidos nas organizações daqueles de arquivo permanente; ou a mudança de ênfase que se verifica da preservação de documentos para o acesso à informação (DOLLAR, 1994) - com documentos eletrônicos tem-se adotado um tratamento mais uniforme, que se inicia no momento em que o próprio item é produzido. Assim, por meio da "arquivística integrada", preconizada por Couture e Rousseau (1998), estes documentos, ainda na fase denominada corrente, são identificados, classificados e descritos para que, quando deslocados, sejam-no de forma organizada, prontos para o acesso tanto ao documento quanto ao seu conteúdo. Esse deslocamento poderá ser físico, quando se tratar de deslocamento de mídia visando ao combate à obsolescência tecnológica, ou um deslocamento de servidor, devido principalmente à freqüência de uso, para que documentos eletrônicos de arquivo que tiveram sua utilidade diminuída, não ocupem espaço na memória de sistemas informatizados que poderiam ser utilizados por outros.

\subsection{Arquivamento}

O CONARQ (2004) define arquivamento como uma "seqüência de operações que visam à guarda ordenada de documentos" nas fases corrente, intermediária e permanente. Essa acepção está relacionada ao acesso físico do documento, seu arranjo e disposição nas estantes, fichários, gavetas etc. Nesse contexto, a guarda ordenada a que se refere a citação obedece a um método de arquivamento, que compreende uma série de "operações que determina a disposição dos documentos de um arquivo ou coleção, uns em relação aos outros, e a identificação de cada unidade" (ARQUIVO NACIONAL, 2005). Esse método de arquivamento poderá ser básico (alfabético, geográfico, numérico etc.) ou padronizado (automático, mnemônico, etc.) (PAES, 2005).

Outra acepção é a que entende o arquivamento como uma ação "pela qual uma autoridade determina a guarda de um documento, cessada a sua tramitação" (ARQUIVO NACIONAL, 2005; CONARQ, 2004). 
No caso dos documentos eletrônicos, de acordo com Bearman (1996), para ser evidência eles devem estar intrinsecamente ligados aos seus metadados e serem inviolados. Onde estão acondicionados fisicamente não importa, contanto que estejam devidamente protegidos e controlados. O conteúdo do documento (ou o documento em si) não precisa estar arquivado juntamente com os metadados que a ele fazem referência.

\subsection{Atividades de referência ou disseminação da informação}

Muitas vezes descritas como atividades desenvolvidas somente nos arquivos permanentes (PAES, 2005), as atividades de referência compreendem todos os processos de acesso e uso dos documentos. Nas fases iniciais do ciclo vital dos documentos, essas atividades ficam a cargo dos produtores dos próprios documentos arquivísticos, mas, na fase permanente, políticas de uso e acesso podem ser sistematizadas com o intuito de: determinar o que deve e o que pode ser consultado; estabelecer como devem ser consultados e manipulados os documentos; e analisar o direito de terceiros sobre os documentos e determinações legais dos responsáveis pela produção dos documentos arquivísticos (PAES, 2005). As atividades mais freqüentes são as de reprodução, que pode ser entendida como o "processo de produção de cópia de um documento no conteúdo e na forma, mas não necessariamente em suas dimensões" (ARQUIVO NACIONAL, 2005); e de utilização, que é o efetivo uso do documento como evidência de uma atividade ou função, ou ainda para fins informacionais, quando da tomada de decisão ou pesquisa.

Será o ambiente eletrônico o responsável por oportunidades e desafios, realizando as funções arquivísticas que relacionam o acesso e o uso dos documentos. Sendo assim, não necessariamente o pesquisador e o arquivista precisam estar no mesmo local para que haja troca, acesso e utilização de documentos arquivísticos10. Será o SIGAD a tecnologia mediadora desse acesso e utilização. Para que ambos os processos ocorram nos moldes e dentro dos princípios arquivísticos, é preciso garantir que a configuração desse sistema esteja voltada para a teoria da arquivologia e esteja, principalmente, engajada em resguardar as características do documento arquivístico eletrônico, através de um plano de classificação bem estruturado, de um processo de captura e descrição seguro e relacionado às normas internacionais, nacionais e às necessidades internas da organização; através de um controle de acesso e de segurança em que se atente tanto aos documentos como aos usuários do sistema.

\footnotetext{
10 Tais oportunidades causam outras discussões que se estendem por determinar os conceitos de "custódia" e "momento pós-custodial", mas que não compreendem o escopo do presente trabalho. Para maiores detalhes sobre essa discussão, sugere-se o texto: BRITO, D. M. A informação arquivística na arquivologia póscustodial. Arquivística.net. Rio de Janeiro, v.1, n.1, p. 31- 50, 2005. Disponível em: <www.arquivistica.net>. Data de acesso: 06 set. 2006
} 


\section{Considerações finais}

O presente artigo objetivou a apresentação dos métodos e procedimentos realizados em arquivos, relacionando as diferenças do tratamento de documentos arquivísticos tradicionais e eletrônicos. Percebeu-se que, com a utilização das novas tecnologias e dos documentos produzidos em meio eletrônico, esses processos não sofreram grandes modificações.

Algumas preocupações, como com as atividades de avaliação e seleção e, conseqüentemente, a aplicação da tabela de temporalidade, foram antecipadas para a fase inicial do ciclo vital dos documentos arquivísticos.

Questão crucial continua sendo a manutenção da proveniência, que a atribuição sistematizada de metadados no processo de captura e descrição de documentos arquivísticos e a classificação se encarregam, mesmo em ambiente eletrônico, de manter. A preservação ganha outras acepções. Preservar não significa, em arquivos, somente deixar acessíveis para gerações futuras os documentos arquivísticos, mas garantir que as características arquivísticas dos documentos sejam mantidas e que 0 hardware e o software não venham a se tornar obstáculo à acessibilidade, ou seja, que os documentos possam continuar sendo acessados e visualizados, independente dos aplicativos que os geraram.

As atividades de referência, também chamadas de disseminação da informação, são as mais beneficiadas pelo aparecimento das novas tecnologias da informação. Novas possibilidades de acessar documentos e obter informações são disponibilizadas pela Internet à comunidade a que se refere ou a que dizem respeito os documentos arquivísticos.

A arquivologia, nesse sentido, torna-se mais ampla - tomando as devidas precauções com o sigilo e o acesso aos documentos -, preocupando-se, além da estrutura formal do documento e sua organicidade, também com o conteúdo e suas possibilidades para a tomada de decisão.

Fica a certeza de que a arquivologia, embora tradicionalmente ligada aos documentos produzidos em papel, está preparada para gerenciar a produção, 0 acesso e a preservação de documentos em ambiente eletrônico, por meio de suas práticas. Os sistemas informatizados de gerenciamento arquivístico de documentos vêm, não só para reunir a gestão da diversidade documental que a contemporaneidade apresentou, mas para permitir que a produção, a utilização e o armazenamento de documentos sejam dinâmicos, eficientes e eficazes.

\section{Referências:}

ARQUIVO NACIONAL. Gestão de documentos: conceitos e procedimentos básicos. Rio de Janeiro: 1995. 49 p. (Publicações técnicas, 47). 
Subsídios para um dicionário brasileiro de terminologia arquivística. Disponível em: <http://www.arquivonacional.gov.br/>. Data de acesso: 22 nov. 2005.

BEARMAN, D. Metadata requirements for evidence. [1996?]. Disponível em: <http://www.archimuse.com/papers/nhprc/evidence.html>. Data de acesso: 06 set. 2006.

1993.

. Record-keeping systems. Archivaria, Ottawa, n. 36, p. 16-36,

BELLOTTO, H. L. Arquivos permanentes: tratamento documental. São Paulo: T. A. Queiroz, 1991. 198p.

CONSELHO NACIONAL DE ARQUIVOS - CONARQ. Câmara Técnica de Documentos Eletrônicos. Glossário de documentos arquivísticos digitais. Rio de Janeiro: CONARQ, 2004.

CONWAY, P. Preservação no universo digital. Rio de Janeiro: Arquivo Nacional, 1997. 32 p. (Projeto conservação preventiva em bibliotecas e arquivos).

COUTURE, C; ROUSSEAU, J. Os fundamentos da disciplina arquivística. Lisboa: Publicações Dom Quixote, 1998. 356 p.

DOLLAR, C. O impacto das tecnologias de informação sobre princípios e práticas de arquivos: algumas considerações. Acervo. Rio de Janeiro, v. 7, n. $1 / 2$, p. 3-38, 1994.

DURANTI, L. Registros documentais contemporâneos como provas de ação. Estudos Históricos, Rio de Janeiro, v. 7, n. 13, 1994, p. 49-64.

EUROPEAN COMMISSION. Interchange of Data Between Administrations IDA. Model Requirements for the Management of Electronic Records MoReq. Bruxelles / Luxembourg: CECA-CEE-CEEA, 2001. 133 p.

IKEMATU, R S. Gestão de metadados: sua evolução na tecnologia da informação. DataGramaZero - Revista de Ciência da Informação, v.2 n.6, $2001 . \quad$ Disponível em: <http://dici.ibict.br/archive/00000308/01/Gest\%C3\%A30 de metadados. pdf>. Data de acesso: 05 set. 2006.

INTERNATIONAL COUNCIL ON ARCHIVES - ICA. Committee on Electronic Records. Guide for managing electronic records from an archival perspective. Paris: International Council on Archives, 1997.

MACNEIL, H. Trusting records: legal, historical and diplomatic perspectives. Dordrecht: Kluwer Academic, 2000 citado por RONDINELLI, R. C. Gerenciamento arquivístico de documentos eletrônicos: uma abordagem teórica da diplomática arquivística contemporânea. 3. ed. Rio de Janeiro: FGV, 2005. 158 p.

NATIONAL ARCHIVES AND RECORDS ADMINISTRATION - NARA. Eletronic Records Archives - ERA. Nara glossary. Disponível em: 
<http://www.archives.gov/era/about/glossary.doc $>$. Data de acesso: 18 jul. 2006.

PAES, M. L. Arquivo: teoria e prática. 3 ed. rev. e ampli. Rio de Janeiro: FGV, 2005. 225 p.

PETERSON, Trudy. Archival principles and records of the new technology. The American Archivist, v. 47, n. 4, p. 382-392, 1984.

REPORTS of the Ad Hoc Committee on Descriptive Standards. In: American Archivist, 52, n. 4, 1989 e American Archivist, 53, n. 1, 1990 apud BEARMAN, D. Record-keeping systems. Archivaria, Ottawa, n. 36, p. 16-36, 1993.

RONDINELLI, R. C. Gerenciamento arquivístico de documentos eletrônicos: uma abordagem teórica da diplomática arquivística contemporânea. 3. ed. Rio de Janeiro: FGV, 2005. 158 p.

SCHELLENBERG, T. Arquivos modernos: princípios e técnicas. 2. ed. Rio de Janeiro: FGV, 2002. 386 p. 